\title{
Towards a computational model of Dyslexia
}

\author{
Sagi Jaffe-Dax*, Ofri Raviv, Nori Jacoby, Yonatan Loewenstein, Merav Ahissar \\ From 24th Annual Computational Neuroscience Meeting: CNS*2015 \\ Prague, Czech Republic. 18-23 July 2015
}

Dyslexics are diagnosed for their poor reading skills. Yet, they characteristically also suffer from poor verbal memory, and often from poor auditory skills. We now hypothesize that dyslexia can be understood computationally as a deficit in integrating prior information with noisy observations. To test this hypothesis we analyzed performance in two tones pitch discrimination task using a twoparameter computational model. One parameter captures the internal noise in representing the current event and the other captures the impact of recently acquired prior

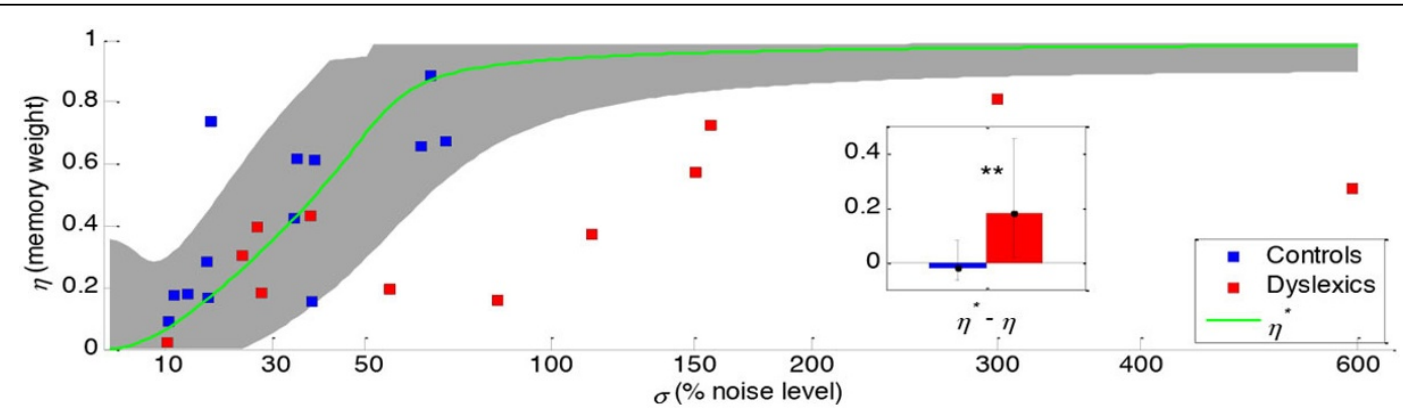

Figure 1 Estimated parameters of the Implicit Memory Model. Estimated values of $\eta$ (weighting of implicit memory) as a function of estimated values of $\sigma$ (percentage of internal noise) of Controls (blue) and Dyslexics (red). The optimal weighting $\eta^{*}$ is plotted in green. Gray area depicts the confidence interval of $2.5 \%$ below the best performance. Inset. Median deviation from optimal weighting of previous trials. Dyslexics' deviation is larger than Controls' (Mann-Whitney test, $Z=2.5, P<0.01$ ). Error bars denote inter-quartile range.
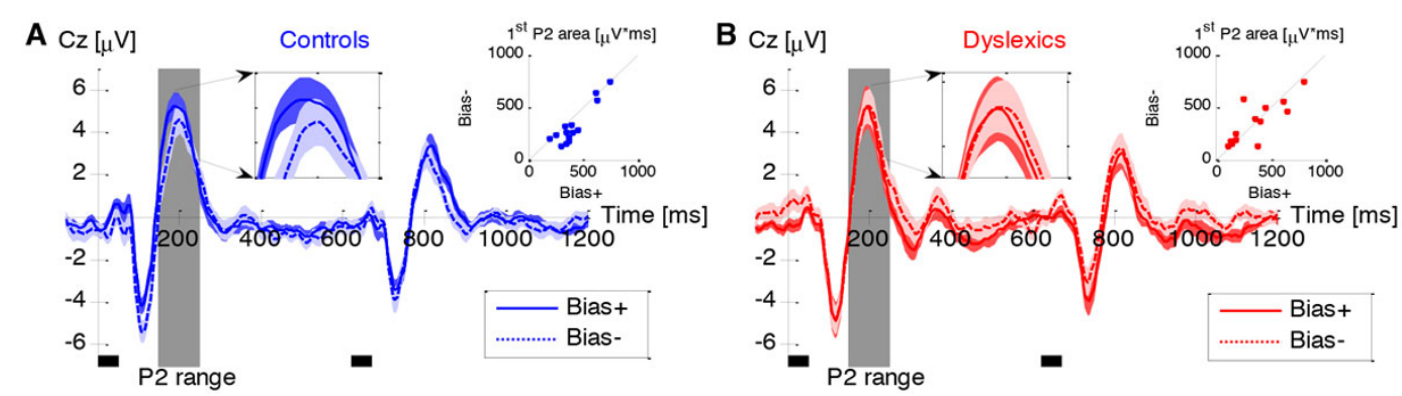

Figure 2 Grand Average ERPs to the two-tone stimulation. A. Controls B. Dyslexics. Trials are sorted according to the trial type, Bias+ (where the impact of previous trials improves performance) and Bias- (where the impact of previous trials impairs performance). Controls' P2 after the first tone differs between the two trial types. Dyslexics' evoked responses did not differ between the two trial types. Filled areas denote crosssubject SEM. Small black rectangles under the plots denote the temporal location of the two tones in the trial. Middle insets. P2 region enlarged; Top right insets. Single subject P2 area in Bias- versus Bias+ trials. The difference between the trial types is significantly larger among Controls than among Dyslexics (Condition $\times$ Group interaction: Mann-Whitney test, $z=2.5, P<0.05$ ).

* Correspondence: sagi.jaffe@mail.huji.ac.il

Edmond and Lily Safra Center for Brain Sciences, The Hebrew University of Jerusalem, Jerusalem 91904, Israel 
information [1]. We found that dyslexics' perceptual deficit can be accounted for by inadequate adjustment of these components: low weighting of their implicit memory in relation to their internal noise (Figure 1). Using ERP measurements we found evidence for dyslexics' deficient automatic integration of experiment's statistics (Figure 2). Taken together, these results suggest that dyslexia can be understood as a well-defined computational deficit.

\section{Acknowledgements}

This work was supported by Israel Science Foundation (grant no. 616/11).

Published: 18 December 2015

\section{Reference}

1. Raviv $\mathrm{O}$, Ahissar $\mathrm{M}$, Loewenstein $\mathrm{Y}$ : How recent history affects perception: the normative approach and its heuristic approximation. PLoS Comput Biol 2012, 8:e1002731.

doi:10.1186/1471-2202-16-S1-012

Cite this article as: Jaffe-Dax et al.: Towards a computational model of Dyslexia. BMC Neuroscience 2015 16(Suppl 1):012.

Submit your next manuscript to BioMed Central and take full advantage of:

- Convenient online submission

- Thorough peer review

- No space constraints or color figure charges

- Immediate publication on acceptance

- Inclusion in PubMed, CAS, Scopus and Google Scholar

- Research which is freely available for redistribution

Submit your manuscript at www.biomedcentral.com/submit
C Biomed Central 